\title{
Project Management Learning Takes Flight
}

\section{Miss Victoria Townsend, University of Windsor}

Victoria Townsend is presently a $\mathrm{PhD}$ candidate in manufacturing systems engineering at the University of Windsor, Canada. In 2012, she completed a university teaching certificate program with the Centre for Teaching and Learning at the University of Windsor. Victoria believes in the value of connecting theory and experience - an appreciation gained from her experience as a Manufacturing Engineer at $3 \mathrm{M}$ and as a Technical Community Relations Manager at the Society of Manufacturing engineers (SME). Her research interests are in engineering education, participatory design in manufacturing systems, and she has also published research in rapid prototyping. Victoria loves to learn and help others to learn.

\section{Dr. (Ruth) Jill Urbanic P.Eng., University of Windsor}

(Ruth) Jill Urbanic received her B. A. Sc. in Mechanical Engineering at the University of Waterloo in Canada. After graduating, she pursued opportunities to work in various advanced manufacturing environments. She has been involved with design, implementation, and support for several types of manufacturing, material handling, testing, gauging and assembly equipment for a variety of engine components and vehicle styles. Dr. Urbanic wished to enhance her practical background with more theoretical knowledge. She received her M. A. Sc. in Industrial Engineering and her Ph. D. in Mechanical Engineering at the University of Windsor, and is a recipient of an NSERC University Faculty Award. She is presently an Associate Professor in the Department of Mechanical, Automotive, and Materials Engineering at the University of Windsor, and teaches courses related to design and technical communication, such as systems design, computer aided design and manufacturing, and the senior design project course. She is the 2013 Wighton Fellow, which is a national award to recognize excellence in the development and teaching of laboratory-based courses in Canadian undergraduate engineering programs. 


\section{Project Management Learning Takes Flight}

\section{Introduction}

Project management is a threshold concept in engineering education, meaning that it is transformative, integrative, and often troublesome for learners ${ }^{[1]}$. For these reasons, it should be developed with deep versus surface learning opportunities ${ }^{[2]}$. The question is: how? What purposeful conditions and contexts can educators create to help students learn project management, and how can it be introduced on a small scale for iterative development?

These questions are explored in this paper with a student-centered, experiential learning project management workshop that has been developed and tested with industrial and mechanical engineering undergraduate students (in capstone courses) and industrial engineering graduate students (in a seminar) over a four year period. This workshop utilizes a relational Structure of Observed Learning Outcomes (SOLO) approach, which intentionally encourages learners to build connections between parts and the whole, to explore the significance and meaning behind these connections, and to connect theory and practice ${ }^{[3]}$. This understanding is critical to learning project management, since project management involves building, and being aware of, relationships between people, purpose, goals, tasks, processes, procedures, environments, resources, settings, time, etc. These relationships are further emphasized by the experiential learning approach, where students interact with and formulate these connections personally in a dynamic system. Specifically, the experiential learning iterative cycle used in this workshop is Deming's plan-do-check-act (PDCA) cycle ${ }^{[4]}$. By combining the SOLO relational and experiential learning approaches as a methodology for the workshop, a learning space is created for each student to challenge, test, find, question, and create project management relationships in a dynamic system. This combination yields the opportunity for each learner to develop situational awareness - a critical trait of a dynamic project manager and decision-maker (and a trait rarely discussed in the engineering education literature).

\section{Methodology}

After being engaged in teaching and learning activities for engineering capstone courses for five years, the authors have found that from year-to-year students have consistently faced several challenges in managing their capstone projects:

- A reluctance to ask questions;

- Feeling "stuck" by constraints (e.g. limited resources and believing that other groups are better off, leading students to believe that their solution space is comparatively smaller);

- Group conflict, with limited use of negotiation in group interactions and an inability to divide work between group members;

- Being unaware of bias (e.g. bias towards a particular solution in the case of formulating pre-conceived solutions before analyzing the problem or project needs); and

- $\quad$ Responding to change (e.g. no contingency planning). 
These are challenges for any project manager and capstone student to face, associated with learning that will require ongoing experience, practice, and development. To help students on this road to development, this workshop aims to address these areas of concern broadly and relationally. From these observations, the following learning outcomes have been created for the workshop. In this workshop, each student will have the opportunity to experience:

1. Asking questions and observing what positive effect may come from asking questions;

2. Challenging constraints and the perception versus reality of constraints;

3. Testing negotiation in a small group setting along with division of work;

4. Questioning bias and the relationship between bias and behaviour;

5. Asking what risks may be present and creating and testing contingency plans in a very small-scale project; and

6. Having a fun experience with a group project and team - all as a reference datum for further learning and development.

Typically, learning outcomes are stated with the stem, "On successful completion of this course, students will be able to... [learning outcomes]." The purpose of this workshop, however, is not aimed at establishing mastery of the six learning outcomes mentioned above; rather, the aim is to provide a setting where students are encouraged to experiment with these aims and challenge the underlying beliefs associated with them (e.g. Can asking questions open new doors? Can a constraint be helpful? Can negotiation lead to group decision-making? Am I biased? Etc.). From these potential learning seeds, students can choose to question their beliefs and see an opportunity to grow from the learning experience with new motivation towards developing their project management knowledge (cognitive learning), skills (performative learning), and beliefs (affective learning) in their capstone project and beyond with informed iteration.

To mobilize these learning outcomes, experiential learning is utilized. In the pedagogical literature, Kolb's experiential learning cycle is often referenced. Kolb's learning cycle consists of a concrete experience (feeling), reflective observation (watching), abstract conceptualisation (thinking), and active experimentation (doing) ${ }^{[5]}$. This is quite similar to Deming's plan (think), do (and feel), check (reflect), and act (revise) learning cycle. Deming's PDCA cycle is used here because it also further grounds the students' learning in industrial engineering practice, as students may have learned about Deming and his work in their studies on quality, management, and continuous improvement, which is also cited in the project management literature ${ }^{\left[6, \mathrm{p}^{.22}\right]}$. This enables the learning strategy to potentially be grounded in the students' past experience and the broader engineering curriculum beyond project management. Identifying this with students further helps them to make these meta-connections.

Deming's learning cycle is operationalized in the project management workshop in three phases: phase 1 (plan), phase 2 (do), and phase 3 (check, act). Appropriate learning methods are aligned to each phase: storytelling and mini-lecture (phase 1), experiential learning activity (phase 2), and discussion and feedback (phase 3 ). These phases also align with increasing levels of Bloom's Taxonomy ${ }^{[7]}$, which brings students into deeper learning as the workshop progresses phase 1 (comprehension), phase 2 (application, analysis, and creation), and phase 3 (evaluation). This learning scaffolding is illustrated in the following pictorial table (Figure 1), which highlights the advancement of the learning into the Bloom and SOLO taxonomies as the 
workshop develops along with the progression through the stages in the Deming cycle (PDCA). The alignment between the Bloom's and SOLO taxonomies is also related ${ }^{[8]}$.

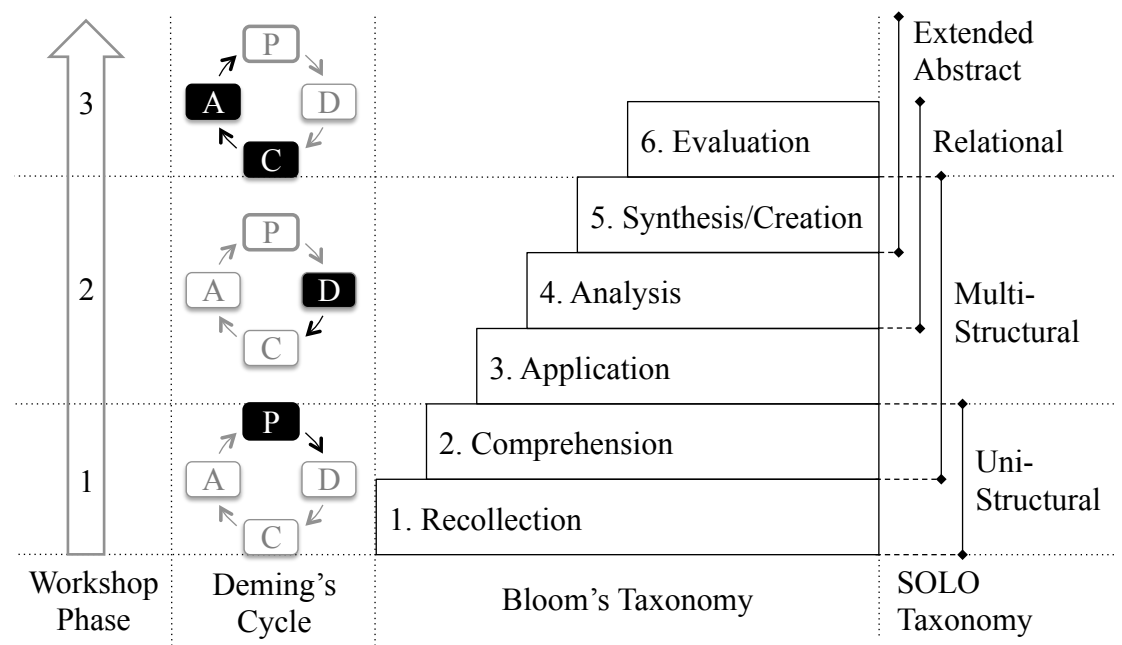

Figure 1: Phases of the Lesson in Alignment with Deming's Cycle and Learning Taxonomies

As Figure 1 illustrates, the aim of this project management workshop is to simultaneously learn by going around (learning cycle) and up (learning taxonomies), which moves students into higher-order thinking, i.e. deep learning, as the workshop progresses.

The workshop, and its three phases, are discussed here in terms of both its framework design (theory) and student participation (experience). This workshop has been conducted five times with undergraduate engineering capstone classes - once with a mechanical engineering capstone class (May 2009) and four times with industrial engineering undergraduate capstone classes (September 2009, October 2010, September 2011, and September 2012). It has also been conducted once with an industrial engineering graduate class of masters and $\mathrm{PhD}$ students in February 2010.

\section{Phase 1: Plan (Comprehend)}

In phase 1, the workshop facilitator begins by briefly ( five minutes) sharing past experience with project management (story telling), highlighting its importance and ubiquity in engineering practice and in personal life. Students are asked to remember a time when they have been involved in managing a project - at school, at work, at home, etc. The purpose of this exercise is to establish common ground and relevance around the topic of project management between the workshop facilitator and the students. This is re-iterated in the presentation slide as: "We have shared context." In other words, we are on this project management journey together.

This brief introduction is followed by a ten-minute mini-lecture that shares fundamental project management concepts utilizing the project management body of knowledge (PMBOK, an ANSI standard $)^{[6]}$. This reference integrates industry and academic sources, which further builds on, and integrates, the relevance of practice and the use of standards within practice. Project management topics discussed include the definition of: a project, project management, and Henri 
Fayol's five major project management process groups. A sampling of the lecture slides illustrating the project management process groups is illustrated in Figure 2.

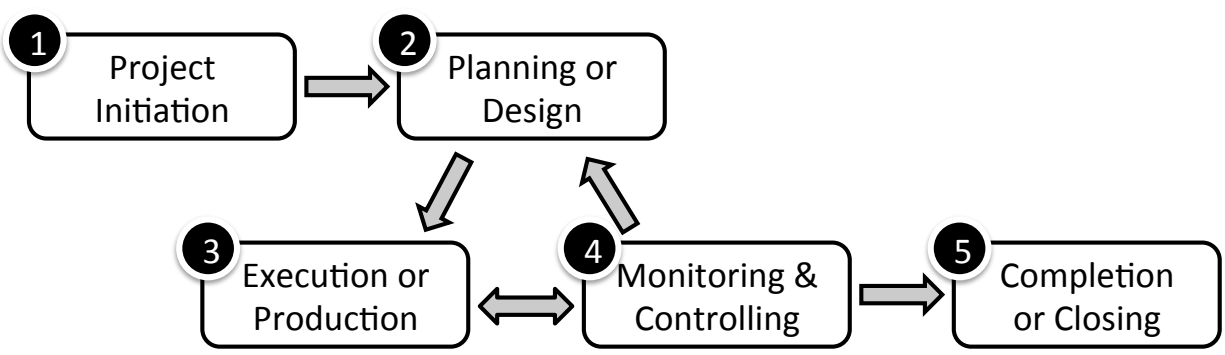

Figure 2: Excerpt of Presentation Slides (Project Management Process Groups ${ }^{[6, p .49]}$ )

\section{Phase 2: Do (Apply, Analyze, and Create)}

In phase 2 of the workshop, a very simple project charter to build a "flying apparatus" is shared with the students; this both models a project charter and provides instruction for the active learning exercise. The charter, Figure 3, states the objective: to experience and reflect on a project management cycle with your team; to plan (design), execute (construct), and monitor (successfully fly) a flying apparatus that yields the "longest flight" (metric of success).

\begin{tabular}{|c|c|c|c|c|}
\hline \multicolumn{5}{|c|}{$\begin{array}{l}\text { Objectives/Goals } \\
\text { - To experience and reflect on a project management cycle with your team; to plan (design), execute } \\
\text { (construct), and monitor (successfully fly) a flying apparatus that yields the longest flight. } \\
\text { - To interpret and apply Henri Fayol's } 5 \text { major stages of project management } \\
\text { - To utilize the conversation cards to question your experience }\end{array}$} \\
\hline \multicolumn{5}{|c|}{$\begin{array}{l}\text { Scope } \\
\text { - Work within groups of approx. } 5 \text { people to design, construct, and fly a "flying apparatus" from } \\
\text { available resources and fly it within the time allotted (Note: constraint). } \\
\text { - The team who fulfills the objectives to the fullest degree is deemed the most "successful" }\end{array}$} \\
\hline \multicolumn{5}{|c|}{$\begin{array}{l}\text { Participants } \\
\quad-\text { IE Capstone students, } 5 \text { people in a group max. (approx. } 6 \text { groups) }\end{array}$} \\
\hline \multicolumn{5}{|c|}{$\begin{array}{l}\text { Timeline - Friday, September } 18 \\
\quad-\quad 11: 15-11: 25 \text { (approx.) - planning \& design stages } \\
\quad-\quad 11: 25-11: 35 \text { (approx.) - execution and monitoring/controlling stages (deliver results!) }\end{array}$} \\
\hline Resources & $\begin{array}{l}\text {-People (groups of 5) } \\
\text {-Paper } \\
\text { - Bristol board } \\
\text { - Foam board }\end{array}$ & $\begin{array}{l}- \text { Fork } \\
\text { - Fasteners } \\
\text { - The Great Outdoors } \\
\text { - Glue }\end{array}$ & $\begin{array}{l}\text {-Tape } \\
\text {-Paper } \\
\text {-Scissors } \\
\text {-Pipe cleaners }\end{array}$ & $\begin{array}{l}\cdot \text { Elastics } \\
\cdot \text { Straws } \\
\cdot \text { Etc. }\end{array}$ \\
\hline
\end{tabular}

Figure 3: Experiential Learning Activity Project Charter

Students are divided into groups and each group receives different resources to work with at their group's table. Some groups receive paper and other groups receive an array of items, including 
tape, scissors, cardboard, pipe cleaners, elastic bands, paper airplane templates and instructions, etc. This is meant to directly mimic that different groups often find themselves with different resources (e.g. in capstone projects).

The timeline is specified: each group has ten minutes to plan (design) and execute (construct) a flying apparatus and ten minutes to monitor (fly) it as a class. In each of the workshops that have been conducted, students have reached the end of the time allotted for the design and execution stages and stated "we need more time" - directly experiencing one of the most common project management frustrations - the time constraint.

At the beginning of the activity, each student is given a contemplation card with an aspect of project management relationships to consider, question, and discuss with their group as they design and construct their flying apparatus. The eight different cards, included in Appendices A and $\mathrm{B}$, address: resources, negotiation, risk and contingency, change, constraints, bias, work breakdown, and asking questions (directly related to the learning outcomes). Cards are used (versus, e.g. writing the ideas on the board) so that students can have the questions beside them while they work with their team, one card for each student with members of the group having different cards. These cards are intended to prompt students to draw out relationships in project management -- e.g. are the resources a constraint or something that can be questioned and negotiated? This introduces questions and themes in anticipation for later class discussion and reflection, with the accountability of each group member to share their group's experience with the questions and themes on their card. In cases where students are engaged more deeply in the learning, the questions and themes change the students' behaviours in the activity (e.g. in some cases, students have questioned if resources are a constraint by bartering their resources with another group, realizing that the initial state of resources is not a fixed state and that the constraint is only perceived).

Students are encouraged to ask questions about the charter and project. Many students "get to work" very quickly focusing on outputs; in the planning and design stages, students typically ask very few questions. The value of questioning unfolds, however, when students reconvene as a class to fly their flying apparatuses. The workshop facilitator asks students to construct the test method, or protocol, for testing and measuring the metric of success ("longest flight") for each group's flying apparatus. Here the ambiguity of "longest flight" reveals itself with multiple meanings (e.g. hang time, horizontal distance, vertical distance). Students then see that the measure of success has been uncertain and ill defined - all while they hold their group's finished "solution" in their hand to what seemed like a simple problem. In this moment, students have the opportunity to collectively engage in situational awareness - to see that a clear definition of success is critical in early project management stages; the value of asking questions to build clarity; and the assumptions that can transfer through multiple stages in project management, amounting to a potentially very serious problem if only detected at the end of the project management cycle. In some cases, students have recognized this uncertainty and ill definition in the design and execution stages, which has made an excellent opportunity to ask the student to state the question/concern in front of the class, applaud her/his insight, and role model negotiation of the measure(s) of success with the class. 


\section{Phase 3: Check and Act (Evaluate)}

After the activity, students are typically buzzing about what they would have done differently. It is prime opportunity for collective sharing - to discuss discrepancies between what students thought would happen, what happened, and what could happen if they were to do the project again. In doing so, the experiential learning in phase 2 becomes an anchor to relate theory to, in order to understand the experience and project management more deeply. This is captured in an after action review, or AAR, which asks students: What went right? What went wrong? The AAR prompts students into appreciative and critical reflection. The discussion typically begins with students' first impressions of their experience and dovetails into relating these insights to the topics and themes in the contemplation cards.

The topics and themes in the contemplation cards can also be used to draw students' attention to key lessons and draw each of the group's members into the class discussion, since each group member holds a different contemplation card. Potential class discussion questions related to each contemplation card are included in Appendix C. One topic that is interesting to begin with is questioning bias. For example, the workshop facilitator can prompt students to consider what bias may have affected their understanding of a "flying apparatus." Results have shown, almost unanimously, that most students assume that a flying apparatus should be a paper airplane, but in reality students could create a ball, a ball and bat, a Frisbee, a sling shot, etc. Thus, the value of asking questions is highlighted for challenging biases and evoking creativity. In addition, students have mentioned that the picture of the airplane and wording on the project charter may have affected their bias (thus recognizing the relationship between themselves, the bias inherent in the project charter, and the corresponding outcome).

Differences in team approaches are discussed and evaluated. Results have shown that teams often take different approaches; for example, some teams design and build one flying apparatus while other teams divide into two sub-teams, build two designs, and test them to select their group's official flying apparatus. Asking students with the latter approach why they took this approach is an opportunity to discuss, and relate this approach to, managing risk and contingency. In the case of the graduate class, it was commonly found that each group member preferred to work independently and create his/her own plane, avoiding team negotiation until the very end when one flying apparatus had to be selected as each group's official flying apparatus. This outcome is an opportunity to ask students why they didn't negotiate, inquire into the underlying beliefs and skills associated with negotiation, and collectively hypothesize alternative strategies (e.g. organizing the work breakdown differently).

Asking the students to highlight any other observations that they think are interesting can surface thought-provoking insights. During the first undergraduate capstone class experience with this workshop, a graduate student observer noted that the winning flying apparatus was the simplest design (a key concept of design). It was a simple paper airplane, constructed out of 8-1/2" x 11" printer paper. Other groups had a plethora of resources, including foam board, scissors, and paper airplane instructions of expert designs. In each of the workshops since, graduate and undergraduate, the simplest plane has continued to be the most successful design, though the notion of the flying apparatus as something other than a plane has yet to be fully embraced by student participants. If/when this occurs, it will be interesting to note this as a paradigm shift in design. What's also interesting is that this insight relates very well to the contemplation card on 
resources. In the workshop, the groups with a plethora of resources tend to become distracted by the resources, while the group with only paper has all of the resources needed. This is an excellent way to segue the discussion towards capstone groups who may feel that they, and their project, are somehow disadvantaged and highlight blessings in disguise.

One of the class discussions is organized as a mind map in Figure 4. The format of the mind map embraces non-linear thinking and highlights the relational learning SOLO taxonomy. It is also a way to document the discussion with students, creating a visual representation of the discussion and an artefact of the discussion that the students can further reflect on at a later time.

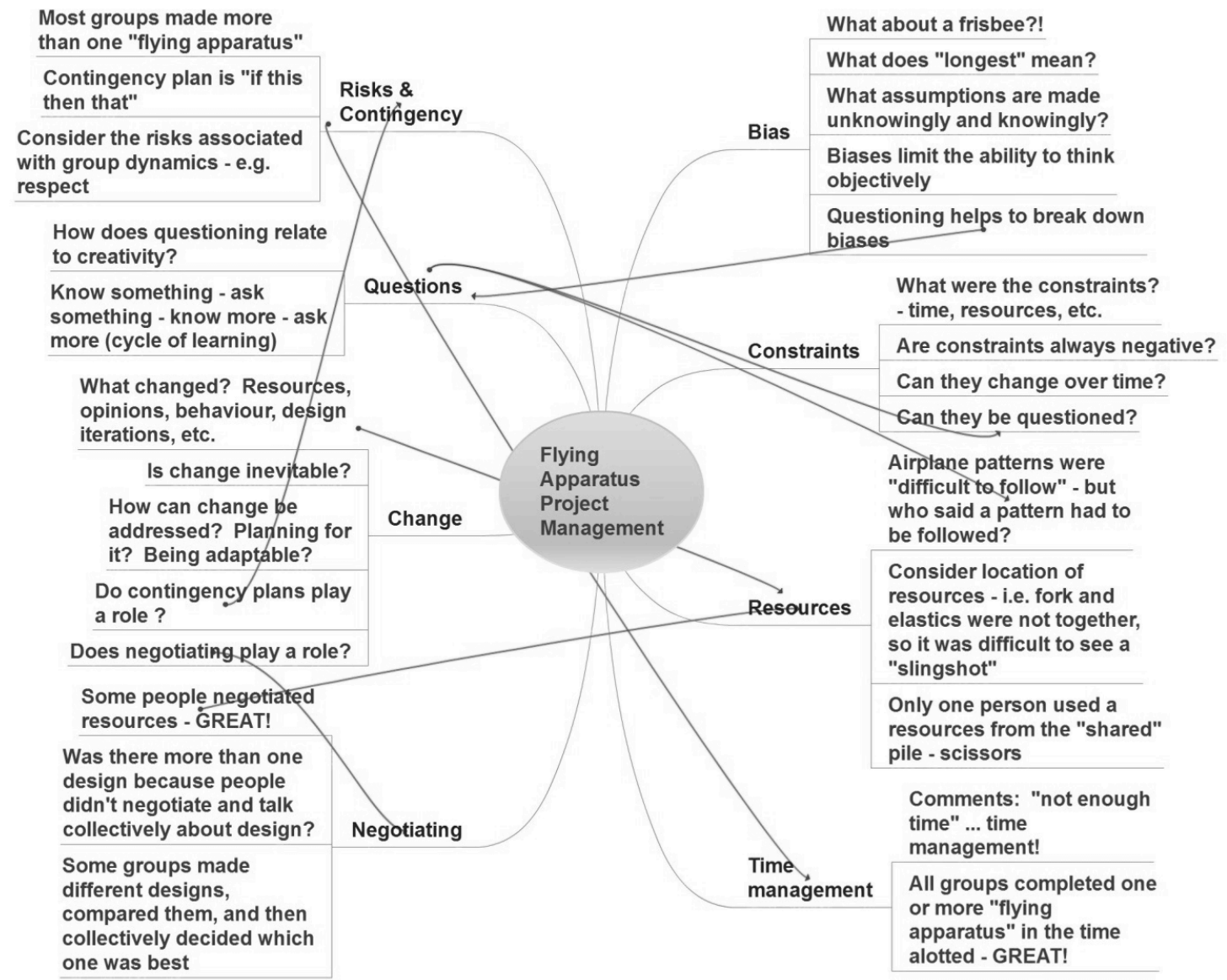

Figure 4: A Mind Map of the Class Discussion and Debrief of the Experiential Learning Activity

While Figure 4 is an example of a class discussion, the purpose of the discussion is not to mimic the outcomes from class to class, but rather to fluidly create a rich relationship of meaning for the students between their unique experiences and the theory. When students discover these concepts, practice these skills, and are emotionally engaged in a simple exercise building a paper airplane, they come to identify and appreciate the gravity of the challenges involved in a larger project particularly when they stumble. In other words, the students co-create and co-validate project management learning in a meaningful context as an anchor for further growth.

Across the different workshops, the class discussion has segued into various directions. Most recently, the students assemble into their capstone groups and then go through a reflection exercise together to further connect the workshop to their capstone project (Appendix D). A list 
of further resources is also shared to encourage students to pursue the development of their project management skills, knowledge, and beliefs in focus areas that have surfaced in their workshop experience. During the small group exercise, students often ask the workshop facilitator to join the small group discussion when they have a problem, question, feel stuck, etc. This is a great opportunity to further connect the workshop learning, and extend this into other resources, in line with the capstone group's needs. It can also be an opportunity for the class to collectively brainstorm potential areas of learning, resources, etc. and share with one another what has been helpful, what hasn't, and what could be.

Following the discussion, students are asked to give feedback on the workshop and their learning in the form of answering the question, "One thing that I learned today was..." This helps the workshop facilitator to understand what each student found as the most influential and critical lesson. It also helps each student to summarize what the workshop has meant to him or her. The feedback results of one class are shown below in Figure 5.

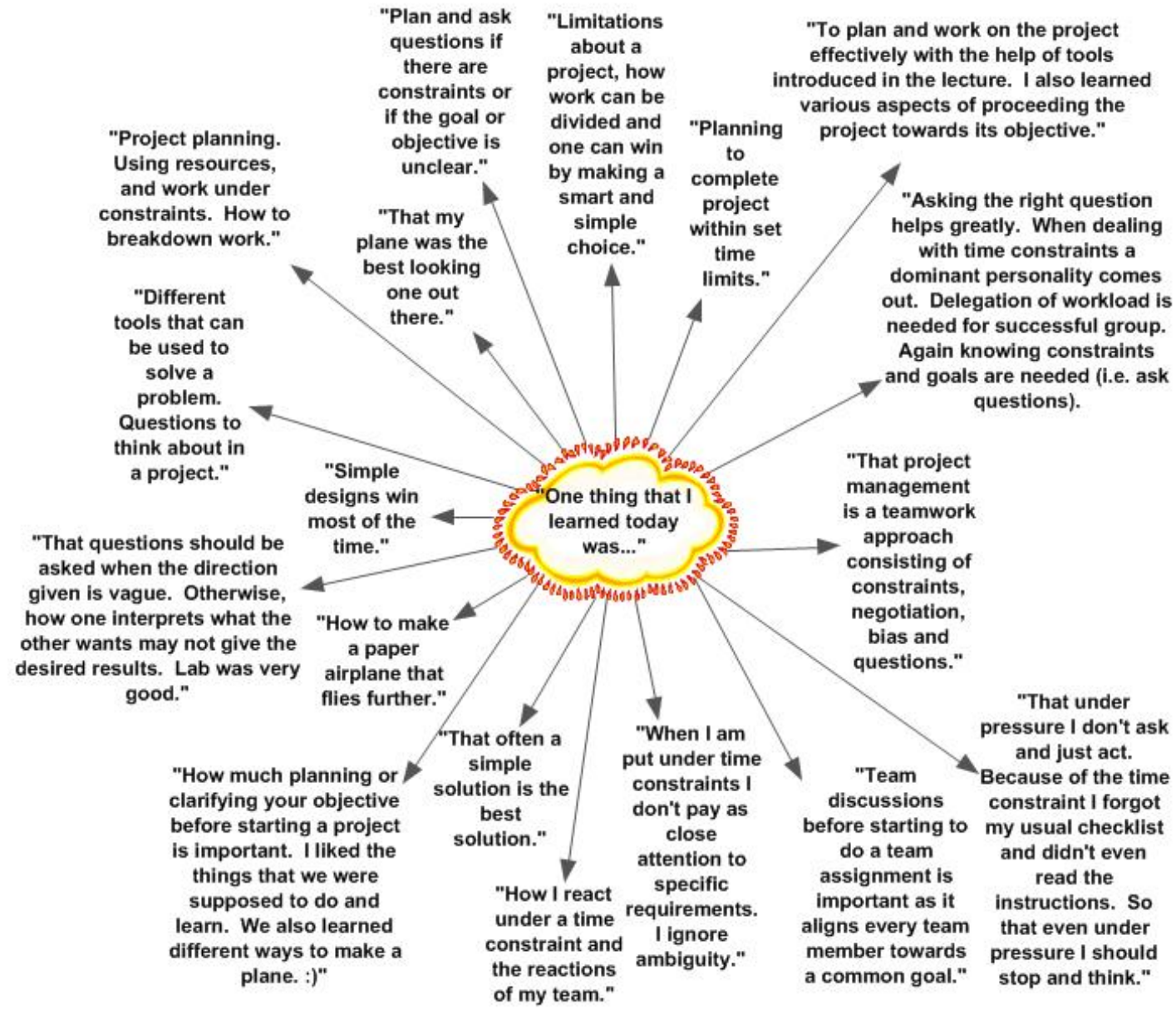

Figure 5: Student Feedback Statements on the Workshop and their Learning

The feedback in Figure 5 articulates the students' expressions of their beliefs relative to project management and their learning experience (relating to the affective domain of learning). This feedback is further related to the learning outcomes in Table 1 and other project management learning interests in Table 2. 
Table 1: Student Feedback Aligned with Learning Outcomes

\begin{tabular}{|l|c|c|c|c|c|c|c|c|c|c|c|c|c|c|c|c|c|c|}
\hline Learning Outcomes & \multicolumn{10}{|c|}{ Student Feedback } \\
\hline 1. Questions & $\boldsymbol{V}$ & & & $\boldsymbol{V}$ & $\boldsymbol{V}$ & $\boldsymbol{V}$ & & & & & & $\boldsymbol{V}$ & $\boldsymbol{V}$ & & \\
\hline 2. Constraints & $\boldsymbol{V}$ & $\boldsymbol{V}$ & $\boldsymbol{V}$ & & $\boldsymbol{V}$ & $\boldsymbol{V}$ & $\boldsymbol{V}$ & & $\boldsymbol{V}$ & $\boldsymbol{V}$ & & & & & & $\boldsymbol{V}$ \\
\hline 3. Negotiation and work breakdown & & $\boldsymbol{V}$ & & & $\boldsymbol{V}$ & $\boldsymbol{V}$ & & & & & & & & & & $\boldsymbol{V}$ & \\
\hline 4. Bias & & & & & & $\boldsymbol{V}$ & & & & & & $\boldsymbol{V}$ & & & & & \\
\hline 5. Risk and contingency & $\boldsymbol{V}$ & & $\boldsymbol{V}$ & $\boldsymbol{V}$ & & & & & & & & $\boldsymbol{V}$ & & & & & \\
\hline 6. Fun & & & & & & & & & & & & $\boldsymbol{V}$ & $\boldsymbol{V}$ & & & & $\boldsymbol{V}$ \\
\hline
\end{tabular}

Table 2: Student Feedback Aligned with Learning Interests (in Addition to Learning Outcomes in Table 1)

\begin{tabular}{|c|c|c|c|c|c|c|c|c|c|c|c|c|c|c|c|c|}
\hline Other Learning Interests Stated & \multicolumn{16}{|c|}{ Student Feedback } \\
\hline Plan & $\boldsymbol{V}$ & & $\checkmark$ & $\checkmark$ & & & & & & & & $\checkmark$ & & & $\boldsymbol{V}$ & \\
\hline Goal / objective & $\boldsymbol{V}$ & & & $\checkmark$ & $\checkmark$ & & & $\boldsymbol{V}$ & & & & $\boldsymbol{V}$ & & & & \\
\hline Smart and simple choice & & $\checkmark$ & & & & & & & & & & & & & & \\
\hline Time limits & & & $\checkmark$ & & & & $\boldsymbol{V}$ & & $\checkmark$ & $\boldsymbol{v}$ & & & & & & \\
\hline Help of tools & & & & $\checkmark$ & & & & & & & & & & $\checkmark$ & & \\
\hline Group personalities & & & & & $\checkmark$ & & & & & & & & & & & \\
\hline Delegation & & & & & $\checkmark$ & & & & & & & & & & & \\
\hline Teamwork & & & & & & $\checkmark$ & & & & & & & & & & \\
\hline Under pressure & & & & & & & $\boldsymbol{V}$ & & $\checkmark$ & & & & & & & \\
\hline Stop and think / reactions & & & & & & & $\boldsymbol{V}$ & & & $\checkmark$ & & & & & & \\
\hline Team discussion & & & & & & & & $\boldsymbol{V}$ & & & & & & & & \\
\hline Ambiguity & & & & & & & & & $\checkmark$ & & & & & & & \\
\hline Attention & & & & & & & & & $\boldsymbol{V}$ & & & & & & & \\
\hline Requirements & & & & & & & & & $\checkmark$ & & & & & & & \\
\hline Simple design & & & & & & & & & & & $\checkmark$ & & & & & \\
\hline Clarifying & & & & & & & & & & & & $\checkmark$ & & & & \\
\hline Interprets & & & & & & & & & & & & & $\checkmark$ & & & \\
\hline Problem solve & & & & & & & & & & & & & & $\boldsymbol{V}$ & & \\
\hline Using resources & & & & & & & & & & & & & & & $\checkmark$ & \\
\hline
\end{tabular}

Table 1 relates the feedback (Figure 5) to the relationships that students have drawn between their experience and the learning outcomes. In addition, students identified twenty other learning interests related to project management (Table 2), which is evidence of the students making the learning their own. Three of the student statements also reflect self-awareness. The feedback form could be further improved by asking students to also comment on, "One thing that I'm going to learn more about is..." This exercise will help students to identify a goal for their own development of project management knowledge, skills, and beliefs and encourage iterative development beyond the workshop. Additional learning activities and assessments that align with the learning outcomes and student-identified learning interests could further develop student learning and inquire into its effect(s) on the students' capstone project management performance.

\section{Conclusion}

This paper outlines the pedagogical grounding and four-year empirical results of a project management workshop conducted with engineering undergraduate and graduate students. The 
workshop utilizes an experiential learning approach, specifically Deming's plan-do-check-act cycle and a SOLO relational approach. Scaffolding the learning into higher-order thinking in Bloom's taxonomy supports deep learning. The experiential learning activity engages students in a project management cycle and encourages situational awareness by using contemplation cards to engage students in asking questions and actively questioning resources, negotiation, risk and contingency, change, constraints, bias, and work breakdown (directly related to the learning outcomes). Mind-maps are used to document and visualize the class discussions, highlighting non-linear thinking and relationships of meaning. Results from student feedback forms identify influential aspects of the workshop for students, which align with the workshop learning outcomes and other project management learning interests identified by students. These results highlight the merits of this workshop in teaching project management as a learning anchor for iterative development. Workshop materials are included in the appendices, so that other educators, in engineering capstone courses for example, can conduct and modify the workshop. In addition to this pragmatic approach, this paper's theoretical grounding in pedagogical literature by synthesis of learning methodologies (a relational SOLO approach with Deming's experiential and iterative cycle) offers further potential for educators to use, challenge, and adapt the learning framework and workshop example in this research for other complex, threshold engineering concepts that could benefit from deep learning and iterative development.

\section{Acknowledgements}

The authors wish to thank the students who have participated in this workshop and shared their feedback, which has helped the authors to learn in many ways. This research has received clearance by the Research Ethics Board of the University of Windsor, REB\# 14-035.

\section{References}

[1] J. H. F. Meyer and R. Land, 2005, "Threshold concepts and troublesome knowledge (2): Epistemological considerations and a conceptual framework for teaching and learning," Higher Education, 49(3): 373-388.

[2] F. Marton and R. Säljö, 1976, "On qualitative differences in learning: I-Outcome and process*," British Journal of Educational Psychology, 46(1): 4-11.

[3] J. B. Biggs and K. F. Collis, 1982, Evaluating the quality of learning: the SOLO taxonomy (structure of the observed learning outcome). New York, NY: Academic Press.

[4] W. E. Deming, 2000, The new economics for industry, government, education, 2nd ed., Cambridge, MA: The MIT Press.

[5] D. A. Kolb, 1984, Experiential learning: experience as the source of learning development. Englewood Cliffs, NJ: Prentice Hall.

[6] 2013, A Guide to the project management body of knowledge (PMBOK Guide), 5th ed., Newton Square, PA: Project Management Institute (PMI), ANSI standard PMI FS-PMBOK-2013.

[7] B. S. Bloom, 1956, Taxonomy of educational objectives: the classification of educational goals Handbook I, New York, NY: McKay.

[8] M. Potter, 2011, "A primer on learning outcomes and the SOLO taxonomy," Windsor, ON: University of Windsor. 
Appendix A: Contemplation Cards

(Approximately 8 members per group)

\section{Resources}

What resources are present, missing, limited, predictable, unpredictable, etc.? What impact does effectively managing resources have?

\section{Change}

What changes over the course of the project? How do the people in the group respond to change? How can change be managed?

\section{Work Breakdown}

What tasks need to be done in order to reach the goal? How does work breakdown affect the project and team?

\section{Bias}

What preferences exist?

What assumptions are being made? Knowingly and unknowingly? How does this affect the project?

\section{Negotiating}

Is there negotiation in the group? What is being negotiated? Why? When? Is negotiation important? How so?

\section{Constraints}

What limitations are present? Does this affect the project scope? Does it make the project easier? Harder? What is constrained?

\section{Questions}

What questions can be asked? Do questions affect knowledge of a boundary? Can questions eliminate or change a perceived boundary?

\section{Risk \& Contingency}

What risks are present? What contingency plans can be put in place to help minimize this risk? A contingency plan addresses: "if this doesn't work then this." What would be an even better statement? 
Appendix B: Contemplation Cards

(Approximately 4 members per group)
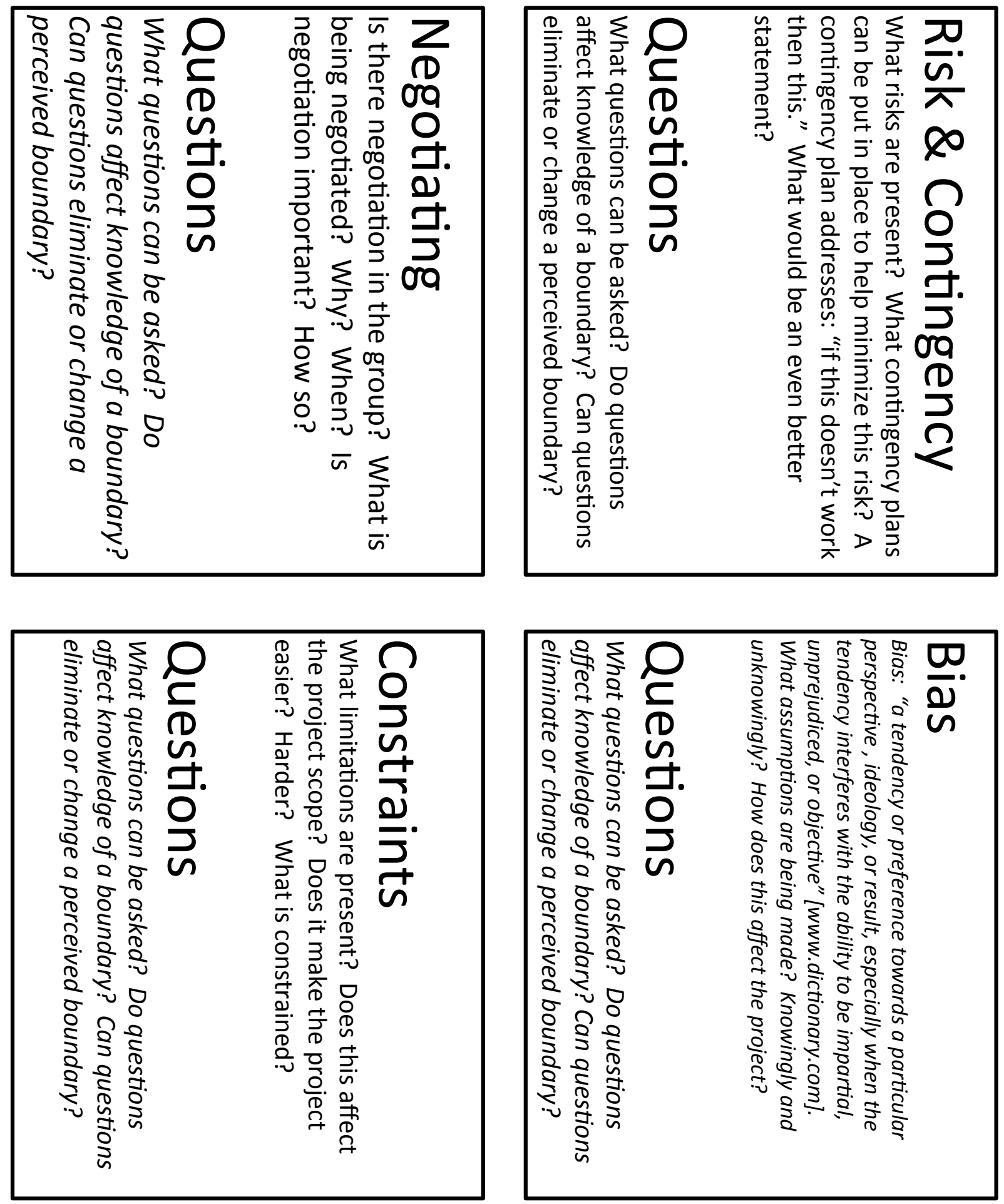


\section{Appendix C: Class Discussion Questions Relating to Contemplation Cards}

The workshop facilitator can begin the class discussion by asking students:

- What do you think went right for your group? In other words, what's important to take note of and appreciate?

- What do you think went wrong for your group? In other words, how can you and your group improve?

- If you were to do the project again, what would you do differently?

- Are there any other observations or experiences that you think are interesting?

Further questions for each contemplation card are listed below if needed. Typically, students enjoy debating their different experiences amongst one another, reasoning with the theory and contemplation card perspectives, and creating their own questions for one another and the workshop facilitator.

Negotiation

- Did you negotiate within your group? Or with other groups? Why or why not?

- If so, what did you negotiate? E.g. resources?

- If so, when did you negotiate? E.g. in the design stage? In the construction stage?

- Can negotiation and creativity be related? I.e. how 2 ideas could be made into one?

- Did respect or trust play a role in your negotiation?

\section{Resources}

- Were the supplied resources helpful?

- Were there too many resources or too few?

- How can resources be related to negotiation? Change? Bias? Constraints?

- Could resources be considered information? Can information be misleading? Missing? Overwhelming?

\section{Change}

- Is change inevitable? Can you avoid change?

- How did you and your group address change? Predict it? Adapt to it?

- How does contingency planning paly a role in addressing change?

- What changes occurred across the project management stages for you and your group?

Questions

- What questions did you ask in the activity? Was it helpful or not helpful? Why?

- What question did you not ask in this workshop but have wanted to?

- How can asking questions relate to learning?

- How can questions affect boundaries? Constraints? Resources? Bias? Risk?

Bias

- What biases or assumptions did you experience or observe? What impact did it have?

- Does a bias limit us? If so or if not, why?

- How can one become aware of bias? What value might this awareness have? 


\section{Constraints}

- What were the constraints for your group?

- Are constraints always fixed? Can they change?

- Can a constraint be helpful? If so or not, why?

Risk and Contingency

- What risks or contingency did you and your group experience or observe?

- If contingency addressees "if this doesn't work then that," what would be an even more useful statement? How about "if this doesn't work by a set time, then that?"

- How might parallel streams of work be beneficial? Or not?

- How are risk and contingency related?

- Are there things that you think should not be risked?

- Are there things that you think should be risked?

Work breakdown

- What were some of the tasks that you performed in the activity?

- Could the tasks have been divided differently amongst your group members? What changes would you make if you were to perform the project again as a team? 


\section{Appendix D: Capstone Group Reflection Exercise}

\section{A Reflection on Project Management and You:}

What does today's workshop mean for your capstone team and your team's capstone project?

\section{Methodologies and Tools}

In today's workshop, we learned about Henri Fayol's methodology for project management. What other methodologies, tools (e.g. software), frameworks, etc. do you think are important for your capstone project? This can include ones you already know and want to apply, ones that you want to become more familiar with, and new ones that you want to learn.

\section{Teamwork and Negotiation}

Last week, you experienced a workshop on teamwork and you learned about the stages of group development (forming, storming, norming, and performing). Did your group experience any of these phases in today's workshop? What did you observe?

Last week, you also discussed and took a survey on Belbin Team roles (coordinator, driver, finisher, monitor-evaluator, originator, resource investigator, and supporter). From the survey, what role was the most dominant for you? In your group today, did you perform in this role? How did your role affect the group work? What roles did your group members perform? Would it have been helpful to have someone performing in one of the other roles?

\section{Resources and Constraints}

What resources and constraints are involved in your capstone project?

\section{Risks and Contingency}

What risks are involved in your capstone project? What contingency plans can you put into place?

\section{Bias}

What bias do you have towards your capstone project? What effect might this bias have on your work, your team, and your project? What can you do to question this bias?

\section{Questions}

What questions do you want to ask regarding your capstone project? Try to name at least 5. 